\title{
Some Observations on Bridges Dynamic Behaviour
}

\author{
Jan B. Obrębski \\ Faculty of Civil Engineering, Warsaw University of Technology, Al. Armii Ludowej 16, Warsaw 00-637, Poland
}

\begin{abstract}
The paper presents rather some conclusions from large investigations over dynamic behaviour of bridges under travelling loads. There, as basic tool was applied the 3D-Time Space Method (3D-TSM) in edition proposed by present author. The method uses four-dimensional space, where besides of usual 3D space, the time is the fourth dimension. The bridge with simply supported steel girder is here modelled by means of theory for thin-walled bars (TWBs). In final calculations, solutions are obtained here on numerical way applying well known and simple Finite Differences Method (FDM). In consequence the task is brought to trivial determination of unknowns from set of linear algebraic equations. There, essential part of these equations is so called dynamical stiffness matrix (DSM). The last is additionally tested by Uniform Criterion (...) for evaluation of bridges Critical States $(\mathrm{CrS})$.
\end{abstract}

Key words: Bridges, dynamic behaviour, critical states, critical velocity, critical length, uniform criterion, 3D-time-space method.

\section{Introduction}

Presented wide results of performed analyses for calculated numerous comparative examples concern of simply supported, one span steel bridge with thin-walled girder, having three closed circuits (Fig. 1b). The compared bridges have lengths $L=50$, $60,70,80,90,100 \mathrm{~m}$, and cross-section (CS) with dimensions $30 \times 6 \mathrm{~m}$, defined in Fig. 1b. The CS is inscribed into square mesh $6 \times 6 \mathrm{~m}$. Applied here 3D-TSM (3D-Time Space Method) description for dynamical tasks gives some important possibilities for determination of: displacements of e.g. bridges or high-rise buildings; to show behaviour of structure in all considered time-moments (structure modes for positions of force $P$ from 1 to 10 in Fig. 1a); critical velocities $\left(V_{c r}\right)$ of load $(s)$ travelling over the bridge; or critical length $\left(L_{c r}\right)$ of bridge answering on traveling mass with given velocity. In the all mentioned cases, the bridge or high-rise buildings are treated as the large TWB (thin-walled bar). In general case it is possible to consider composite CSs.

Corresponding author: Jan B. Obrębski, full professor, research fields: structural mechanics, space bar structures, thin-walled bars, strength of materials, programming, and computer methods.

\section{Applied Analysis}

For dynamical analysis of bridges were used motion equations from theory of TWBs [1] implemented to four-dimensional space-3D-TSM. The differential equations of motion by means of FD (finite differences) were transformed into global DSM (dynamical stiffness matrix) of whole task.

In computer structural mechanics is well known global Equilibrium Equation (EE) in matrix form, expressing relation of displacements $x$ to external forces $Q$ :

$$
K x=Q
$$

where, $K$ is stiffness matrix (SM) or DSM, $x$ is vector unknowns and $Q$ is vector of loadings. Determination of unknowns from Eq. (1) can be done in some ways. There, among the others can be applied Cramer's method: $x_{j}=D_{j} / D$, where, $D=\Delta=$ $\operatorname{det}(K)$ is value of the main determinant of coefficients (or functions) of the matrix $K$. Determinant $D_{j}$ is obtained replacing in $D$ the $\mathrm{j}$-th column by column of (loadings) free terms $Q$. So, the case, when

$$
D=0 \text { means } x_{j} \rightarrow \infty
$$

and next

$$
(D=0) \rightarrow(G C=C r S)
$$




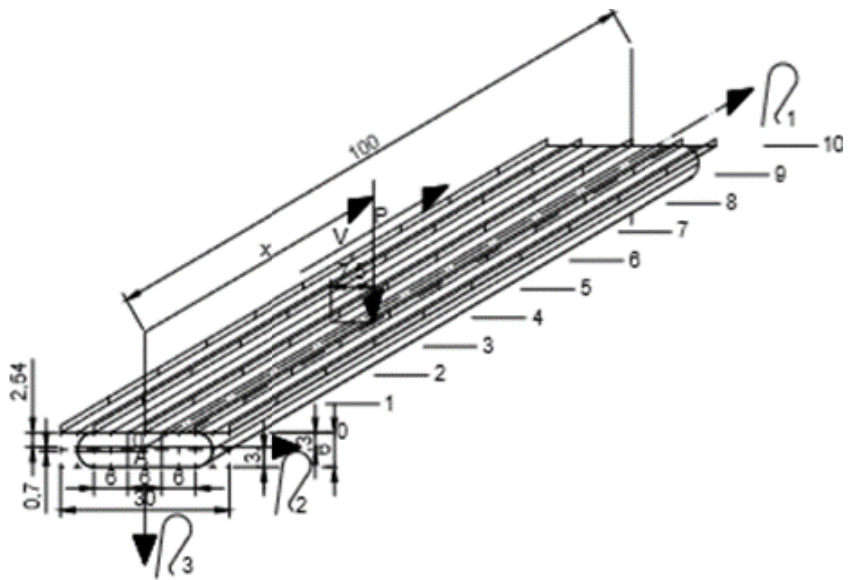

(a)

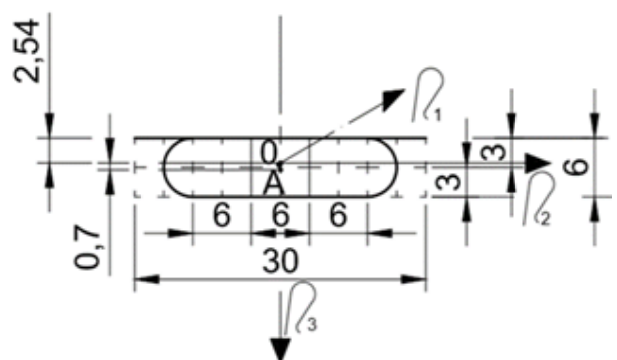

(b)

Fig. 1 (a) Axonometric view on bridge with moving load and (b) shown cross-section of girder. Visible force $P$ and division of girder on 10 sections. Centre of gravity and shearing centre are shown.

So, it signalizes critical state $(\mathrm{CrS})$ or geometrical changeability (GC) of analysed structure. The condition Eq. (2a) was used in Ref. [2] for checking of input data to program. Similarly, condition Eq. (2) was used in analytical solutions [3-5]. The matrix $K$ in Eq. (1) can be composed on basis of any analytical theories or numerically by means of FD (see e.g. Ref. [6]), FEM or e.g. by Difference-Matrix Equation Method (DMEM [1, 7]).

\subsection{Used Equilibrium Equations}

In theory of TWBs [1] are used four differential EEs. It embraces the straight prismatic bars with any CSs homogenous, composite, open, closed and open-closed-with a few closed circuits etc. After special calculations and led step by step tests, now we can regard the formulae derived for the theory of TWB as valid for any type prismatic composite straight bars with any type CSs. This theory [1] is constructed for first and second order, for static, dynamic, stability and dynamic-stability. There is possibility taking into consideration interaction of the bar with surrounding medium, etc. Below, is omitted the first equation for longitudinal forces. Moreover, in considered tasks we have not bending in horizontal direction and therefore the second equation is neglected, too. Finally, in tested tasks were used two independent equations (for vertical bending containing deflections w Eq. (3) $)_{1}$ and torsion $\Theta$ Eq. (3) $)_{2}$ ), only Refs. [8-11]:

$$
\begin{gathered}
\bar{E} \bar{I}_{2} v_{3}^{I V}+\mu \ddot{v}_{3}-\ddot{v}_{3} I_{2 m}=q_{3}^{w}, \\
\bar{E} \bar{I}_{\hat{\omega}} \Theta^{I V}-K_{s} \Theta "+\ddot{\Theta}\left[I_{2 m}+I_{3 m}+\mu\left(\eta_{3 A}\right)^{2}\right]-\ddot{\Theta} " I_{\hat{\omega} m}=m_{1}^{w} .
\end{gathered}
$$

The above differential equations were formally transformed into Finite Differences Operators (FDO) (see Ref. [6]) to the following shape $[9,10]$ :

Bending

$$
\begin{aligned}
w_{t-1, i-1} K_{1} & +w_{t-1, i} K_{2}+w_{t-1, i+1} K_{1}+ \\
+w_{t, i-2} & +w_{t, i-1} K_{3}+w_{t, i} K_{4}+w_{t, i+1} K_{3}+w_{t, i+2}+ \\
& +w_{t+1, i-1} K_{1}+w_{t+1, i} K_{2}+w_{t+1, i+1} K_{1}=Q,
\end{aligned}
$$

Symbols $K_{i}$ and $G_{i}$ mean certain coefficients [9]. In both above equations three rows are describing three
Torsion

$$
\begin{aligned}
\Theta_{t-1, i-1} G_{1} & +\Theta_{t-1, i} G_{2}+\Theta_{t-1, i+1} G_{1}+ \\
+\Theta_{t, i-2} & +\Theta_{t, i-1} G_{3}+\Theta_{t, i} G_{4}+\Theta_{t, i+1} G_{3}+\Theta_{t, i+2}+ \\
& +\Theta_{t+1, i-1} G_{1}+\Theta_{t+1, i} G_{2}+\Theta_{t+1, i+1} G_{1}=S .
\end{aligned}
$$

sequential time moments. Eq. (4) are two independent FDO. There, the vertical deflections are denoted: 
$w=v_{3}$ and lower indices in brackets, separated by coma $(t, i)$-indicate actual point in time-3D space. The same point "i" of girder division (Fig. 1) in previous moment is denoted as $(t-1, i)$ and for the next time moment as $(t+1, i)$. Similarly, at time moment " $t$ " previous points of girder division are denoted as $(t$, $i-2),(t, i-1)$ and next sequential points as $(t, i+1),(t$, $i+2)$. The torsion angles are denoted as " $\Theta$ ".

\subsection{Difference-Matrix Equation Method (DMEM)}

It was the first theory elaborated by Obrębski [1,7], oriented on static or dynamic analyses and synthesis of Space Bar Structures (SBS), with possible simplifications for plane bar-grids, shields and plates. It was oriented on application of numerical algorithms for some computer programs. Important advantage of this method with comparison to FEM (Finite Element Method) is much smoother, fluent manner of composition of global SM for whole SBS. There, equilibrium of one node is described by matrix type equation applying Boole's displacement operators.

\subsection{Application of Four-Dimensional Space: 3D-Time Space Method (3D-TSM)}

Dynamical tasks can be solved for single bars in traditional-analytical way, what is well known in wide up to now literature, but can be also analysed by means of 3D-TSM which gives many new possibilities. There, solutions are led in the four-dimensional space. Here, traditional 3D space is extended on the fourth for time. The idea was developed by several authors and in Poland by Kączkowski [11] and his co-workers. Certain step ahead was done in the doctor theses of R. Szmit (supervised by Obrębski, 2000), by dynamical analysis of tall buildings. There, were used four differential equations for TWB [1], transformed to FDO used in 3D-TSM. Simultaneously, the method was applied by its originator to masses (forces) travelling on bridges, plates, roads and airport landing belts. This paper is the next important step showing application of such description to dynamical stability of bridges under mowing loads. First time it was presented in Ref. [12] at 2004.

In the case of 3D-TSM, writing Eqs. (4), for all points " $\mathrm{i}$ " of the bar division, we obtain DSM, containing information about scheme of girder, its boundary conditions, velocities and positions of vehicle(s) on bridge for all discrete time moments, Fig. 2. In consequence the task is coming to solution of the two separate sets of linear algebraic equation type (1) (for bending and for torsion). They have band, symmetrical character. Moreover, in own program DGPST was used upper half band of K (see Eq. (1)), completed by column of "loadings" $\mathrm{Q}_{\mathrm{i}}$, Fig. 2.

It can be used on each node one Eq. left or right, see Eq. (4). But when for each point of the girder are used two $(d=2)$ or more equations, in such (here) are applied both Eqs. 4. So, in the second case we say, that it is used Difference-Matrix Equation Method (DMEM-description applied in computer program WDKM [7] for SBS), see Fig. 2. Space 3D-time from numerical point of view belongs to $2 \mathrm{D}$ tasks. There, we have equilibrium state of whole structure Eq. (1), taken together for all time moments (in Fig. 2 for 9 moments). Here global matrix $\mathbf{K}_{\mathbf{G}}[G \times G]$ as DSM [9] has number of rows and columns equal $G=N \times T$ and $T=$ number of considered time moments with time distance $\Delta t, N=n \times d, n=p-1=$ number of nodes (points of girder division), $p$-number of sections for girder division, $d$ means number equations used for each node, e.g. one to four as Eq. (4). Each element of global DSM is a traditional stiffness matrix $\mathbf{K}[N \times N]$ [8-10]. Moreover, boundary conditions for girder are taken into account traditionally [6] and for initial time $t=0$ (known or equal zero) and final-usually as "back" difference. Dependently on assumed sequence of unknowns in nodes, the shape of matrices $\mathbf{K}$ and $\mathbf{K}_{\mathbf{G}}$ can be a little other [9].

As the first natural application of Eq. (1) is determination of unknown $x$. In result we obtain deflections w or torsion angles $\Theta$ (see Ref. [13]) three examples of such calculations are given in Fig. 3. 


\begin{tabular}{|c|c|c|c|c|c|c|c|c|c|c|}
\hline Time moment & $t=1$ & $t=2$ & $t=3$ & $t=4$ & $t=5$ & $t=6$ & $t=7$ & $t=8$ & $t=9$ & \\
\hline$t=1$ & $\mathrm{~K}_{\mathrm{r}}$ & $\mathrm{V}_{\mathrm{r}}$ & & & & & & & & $\mathrm{Q}_{1}$ \\
\hline & $\mathrm{V}_{\mathrm{r}}$ & $\mathrm{K}_{\mathrm{r}}$ & $\mathrm{V}_{\mathrm{r}}$ & & & & & & & $\mathrm{Q}_{2}$ \\
\hline$t=2$ & & $\mathrm{~V}_{\mathrm{r}}$ & $\mathrm{K}_{\mathrm{r}}$ & $\mathrm{V}_{\mathrm{r}}$ & & & & & & $\mathrm{Q}_{3}$ \\
\hline$t=4$ & & & $\mathrm{~V}_{\mathrm{r}}$ & $\mathrm{K}_{\mathrm{r}}$ & $\mathrm{V}_{\mathrm{r}}$ & & & & & $\mathrm{Q}_{4}$ \\
\hline$t=5$ & & & & $\mathrm{~V}_{\mathrm{r}}$ & $\mathrm{K}_{\mathrm{r}}$ & $\mathrm{V}_{\mathrm{r}}$ & & & & $\mathrm{Q}_{5}$ \\
\hline$t=6$ & & & & & $\mathrm{~V}_{\mathrm{r}}$ & $\mathrm{K}_{\mathrm{r}}$ & $\mathrm{V}_{\mathrm{r}}$ & & & $\mathrm{Q}_{6}$ \\
\hline$t=7$ & & & & & & $\mathrm{~V}_{\mathrm{r}}$ & $\mathrm{K}_{\mathrm{r}}$ & $\mathrm{V}_{\mathrm{r}}$ & & $\mathrm{Q}_{7}$ \\
\hline$t=8$ & & & & & & & $\mathrm{~V}_{\mathrm{r}}$ & $\mathrm{K}_{\mathrm{r}}$ & $\mathrm{V}_{\mathrm{r}}$ & $\mathrm{Q}_{8}$ \\
\hline$t=9$ & & & & & & & & $\mathrm{~V}_{\mathrm{r}}$ & $\mathrm{K}_{\mathrm{r}}$ & $\mathrm{Q}_{9}$ \\
\hline
\end{tabular}

Fig. 2 DSM Eq. (1) $-K$ and terms $Q$ for the bar, when $p=10, n=9, T=9$, by uniform motion. All sub-matrices have dimensions: $K_{r}[9 \times 9], V_{r}[9 \times 9]$. Here, the load is on bridge, only (case "bridge").
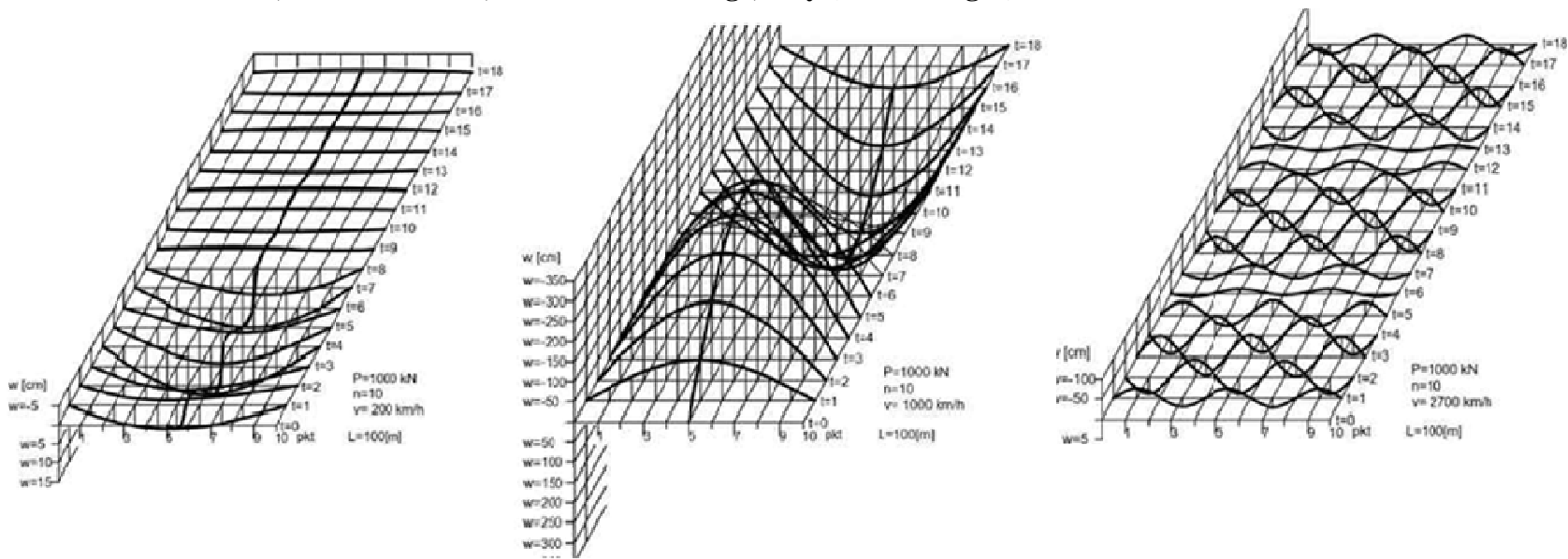

Fig. 3 Calculated vertical displacements (deflections) for bridge with $L=100 \mathrm{~m}, p=10$, under travelling force $P=1,000 \mathrm{kN}$ with velocities $200 \mathrm{~km} / \mathrm{h}$ (up to $15 \mathrm{~cm}$ ); with $v=1,000 \mathrm{~km} / \mathrm{h}$ (up to $350 \mathrm{~cm}$ ) and by 2,700 km/h (up to $100 \mathrm{~cm}$ ). Results are shown for $T_{z}=18$ (case “task"), when last 9-time moments force $P$ is travelling behind bridge.

\subsection{Uniform Criterion (UC)}

The criterion represented by Eq. (2) can be here shown in a little extended form:

$$
D=\Delta=\operatorname{det}[K(P, \omega, v, a, m, M, d, t)]=0
$$

where symbolically: $P$ - any type combined external loading, $\omega$-frequency of vibrations, $v$-velocity of travelling mass, $a$-loading acceleration, $m$-mass of structure (bridge, tall building), $M$-travelling mass, $d$-dumping, $t$-time. Next parameters, which are difficult to show in Eqs. (1) and (5), are: type of cross-section (full, thin-walled etc.), properties of used materials for composite CSs, location of materials in area of CS, structure boundary conditions, interaction of structure with surrounding media etc. The above list of parameters can be much longer. On multicriterial character of critical states of structures, presented in various tasks by worldwide literature, has turned attention of Obrębski [12] in Cape Town and in Ithaca, USA [14]. From that times were started more systematic investigations influence of particular parameters and structure properties on its critical state.

Each change of a sign of D means critical state. So, by application of UC-Eq. (5), a mathematic 
key-operation is comparison to zero main determinant of SM: $D=0$ of the various types' tasks. The SM is denoted as $K$ in fundamental EE (Eq. (1)) of matrix type. It can be composed as set of one EE (Euler) or a few differential EEs $[1,3,5,7]$ or by FD, FEM, DMEM in computer programs (e.g. Ref. [5]). From mathematical point of view by numerical solutions Eq. (1) it is set of linear algebraic equations. It is important, that in all theories and computer algorithms applied in programs written by Obrębski, always was used Eq. (1), only! As well for static, dynamic approaches with theory of first or second order, as with interactions of structure with surrounding media, big shearing forces etc., too.

Through years were tested by Obrębski some methods for determination of critical loadings. They were analytical, numerical and hybrid solutions, e.g. Refs. [1, 6, 7]. In the beginning test for single bars was done, applying DMEM implemented in computer program WDKM [7] and using FDM. Next, analytical tests on behaviour of dynamical stability of bar loaded by axial force and vibrating were done [1]. After it was verified $\mathrm{CrS}$ of bars under combined external loading with different boundary conditions and composite bars with some CSs: thin-walled, open, closed, full etc. At last, attention was turned on tall-buildings and bridges under loading travelling with some velocities (all summarized in Ref. [15]).

\section{Tested Bridges}

The investigated almost-real bridges have 6 lengths 50-100 m (Section 1). The considered CSs are not to the end real, for the reason omitting of reinforced plate over the girder, protecting steel girder against deformation by vehicles. Therefore, mass, rigidity and proper geometrical characteristics are smaller and girder is feebler. In all tested tasks the bridges have scheme shown in Fig. 1b, but thickness of theirs walls assures static deflection of whole girder close to $1 / 1,000$ of their span (L). So, the area of CS and the mass of each bridge are another.
The girders have in both directions three traffic belts for cars and belt for bicycles and pedestrian. There, the one mass 20 or $100 \mathrm{t}$ (approximated by 200 or $1,000 \mathrm{kN}$ ) is travelling with uniform motion along the outward belt, with eccentricity $7.5 \mathrm{~m}$, with velocities $v=50,100,200,300, \ldots, 600 \mathrm{~km} / \mathrm{h}$ (and in a few tasks $v=1200,1500,1800,2100,2400,2700$ $\mathrm{km} / \mathrm{h}$ ). Additionally, there were considered divisions of girder on: $p=8$ or 10 sections. The last permits evaluation of influence of density division of girder on accuracy of calculated results by FDM and 3D-TSM.

The girders of bridges are simply supported, only. There are not considered dumping of interaction between travelling mass and girder. The smaller mass of bridge in relation to travelling masses permits easier observation of critical states of bridge. Dimensions of calculated tasks are shown in Tables 1 and 2. Here, $d$ means number of degrees of freedom (used equations), column "bridge" concerns the task, when move of load along bridge is analysed, only (T). Contrary data in columns "task" show parameters for case, when investigating bridge behaviour under loading moving over girder and after leaving it and travelling further through next $\mathrm{T}$ time moments up to $T_{z}$.

\section{Obtained Results}

The significant part of results was presented on previous conferences. So, in Refs. [9, 10] were given wide lists of calculated geometrical characteristics of CSs for analysed girders, coefficients $K_{i}$ and $G_{i}$, see Eq. (4) and values of $\Delta$ for particular DSMs.

At last in Ref. [13] are shown diagrams of deflections (vertical displacements) and rotations of all calculated tasks. Moreover, graphs were given approximating the critical values of $\mathrm{V}_{\mathrm{cr}}$ and $\mathrm{L}_{\mathrm{cr}}$ for all tasks in variants for $P=200$ or $1,000 \mathrm{kN}$, for considered velocities $v=50-2,700 \mathrm{~km} / \mathrm{h}$ and for division of girder on $p=8$ or 10 sections. Now, some comments and analysis of obtained results are presented. 


\subsection{Critical Velocities}

On the basis of Ref. [13] diagrams of transversal displacements w and torsion angles $\Theta$ are formulated some more important following conclusions.

As critical value of velocity is regarded point, where value of $\mathrm{D}=\Delta$ - change its sign according to Eq. (2) or (5), in such case, deflections and/or torsion of bridge should be increasing to infinity. Values of critical velocities $\mathrm{V}_{\text {cr }}$ are given in Tables 3-6.

Up to velocity of $200 \mathrm{~km} / \mathrm{h}$ values of deflections for all girders were rather similar to static ones.

In the case, when $v=50 \mathrm{~km} / \mathrm{h}$, deflections of bridge disappear just at the moment, when loading go out of the girder-at time moment $\mathrm{T}$.

But, in the case when loading is travelling with $v=200 \mathrm{~km} / \mathrm{h}$ or higher, after leaving of girder by travelling mass, small vibrations of bridge are observed up to last time moment $\mathrm{T}_{\mathrm{z}}$.

The biggest unnormal values of transverse displacements were obtained for velocities: $900 \mathrm{~km} / \mathrm{h}$ $(2.5 \mathrm{~m}), 1,000 \mathrm{~km} / \mathrm{h}(3.5 \mathrm{~m})$; and chaotic for 2,700 $\mathrm{km} / \mathrm{h}(1 \mathrm{~m})$.

Maximal, approximate calculated absolute deflections of bridge are shown in Table 2.

It is interesting, that by high velocities, the girder has tendency to lift up.

\subsection{Critical Lengths of Bridge}

There as critical length of girder by uniform motion of mass travelling with given velocity, is regarded such value $L_{c r}$ resulting by $\mathrm{D}=\Delta=0$ - change its sign

Table 1 The essential parameters of comparative tasks in function of $p$-number of sections assumed for girder.

\begin{tabular}{llllllllll}
\hline Points & Nodes & DOF & Dimension & \multicolumn{2}{c}{ Bridge } \\
\hline$p$ & $n=p-1$ & $d$ & $N=d \times n$ & $T=n$ & $G=N \times T$ & $N_{e}=G \times G$ & $T_{z}=2 \times n$ & $G_{z}=N \times T_{z}$ & $N_{e z}=G_{z} \times G_{z}$ \\
8 & 7 & 1 & 7 & 7 & 49 & 2,401 & 14 & 98 & 9,604 \\
10 & 9 & 1 & 9 & 9 & 81 & 6,561 & 18 & 162 & 26,244 \\
\hline
\end{tabular}

Table 2 Calculated absolute values of bridge girder deflections by particular velocities of $P=1,000 \mathrm{kN}$.

\begin{tabular}{|c|c|c|c|c|c|c|c|c|c|c|c|c|c|c|c|c|c|c|c|}
\hline$v(\mathrm{~km} / \mathrm{h})$ & 0 & 50 & 100 & 200 & 300 & 400 & 500 & 600 & 700 & 800 & 900 & 1,000 & 1,100 & 1,200 & 1,500 & 1,800 & 2,100 & 2,400 & 2,700 \\
\hline$w(\mathrm{~cm})$ & 10 & 10 & 10 & 15 & 30 & 25 & 35 & 25 & 30 & 20 & 250 & 350 & 25 & 15 & 15 & 30 & 35 & 15 & 100 \\
\hline
\end{tabular}

Table 3 Critical velocities $(\mathrm{km} / \mathrm{h})$ for travelling force $P=1,000 \mathrm{kN}$; bridge, only.

\begin{tabular}{|c|c|c|c|c|}
\hline \multirow[b]{2}{*}{$L(\mathrm{~m})$} & \multicolumn{2}{|c|}{$p=10$} & \multicolumn{2}{|c|}{$p=8$} \\
\hline & Bending & Torsion & Bending & Torsion \\
\hline 50 & 900 & 850 & & 75,150 \\
\hline 60 & 150,420 & $150,440,830$ & 150 & $75,240,440,830$ \\
\hline 70 & 240 & 150 & 250,850 & $75,150,430$ \\
\hline 80 & $70,150,840$ & $150,250,450,830$ & 250,440 & $75,150,250$ \\
\hline 90 & 440,840 & $150,250,430,830$ & $150,250,440$ & $75,150,250,430,830$ \\
\hline 100 & $\begin{array}{l}160,250,350,550,650, \\
750,850,1950,2120,2550\end{array}$ & $\begin{array}{l}75,150,250,750,85,1150 \\
1200,1640\end{array}$ & 870 & $75,150,250,320$ \\
\hline
\end{tabular}

Table 4 Critical velocities $(\mathrm{km} / \mathrm{h})$ for travelling force $P=1,000 \mathrm{kN}$; task.

\begin{tabular}{|c|c|c|c|c|}
\hline \multirow[b]{2}{*}{$L(\mathrm{~m})$} & \multicolumn{2}{|c|}{$p=10$} & \multicolumn{2}{|c|}{$p=8$} \\
\hline & Bending & Torsion & Bending & Torsion \\
\hline 50 & 900 & & 870 & 75,250 \\
\hline 60 & 150,430 & & 150,440 & $150,410,820$ \\
\hline 70 & & & 150,840 & 150,830 \\
\hline 80 & 150,430 & & 150,870 & $240,450,830$ \\
\hline 90 & 240 & & $150,430,880$ & $240,440,820$ \\
\hline 100 & $\begin{array}{l}150,250,350,450,550, \\
650,850,950,1150,1550\end{array}$ & $\begin{array}{l}150,350,780,930,1140, \\
1470,1540,2220,2540\end{array}$ & 240,880 & 250,430 \\
\hline
\end{tabular}


Table 5 Critical velocities $(\mathrm{km} / \mathrm{h})$ for travelling force $P=200 \mathrm{kN}$; bridge, only.

\begin{tabular}{lllll}
\hline & & $n=10$ & $n=8$ \\
\hline$L(\mathrm{~m})$ & Bending & Torsion & Bending & Torsion \\
\hline 50 & 850 & & 870 & 75,250 \\
60 & $150,430,830$ & $150,430,830$ & 150 & $75,250,440,820$ \\
70 & 250 & 150 & 250,870 & $75,150,440$ \\
80 & & $150,250,440,820$ & 250,430 & $75,150,250$ \\
90 & $75,250,430$ & $150,250,450,820$ & $150,250,430,870$ & $75,150,250,450,830$ \\
100 & 150,850 & $150,250,440$ & $180,250,430,870$ & $75,150,250,440$ \\
\hline
\end{tabular}

Table 6 Critical velocities $(\mathrm{km} / \mathrm{h})$ for travelling force $P=200 \mathrm{kN}$; task.

\begin{tabular}{lllll}
\hline & \multicolumn{5}{c}{$n=10$} & $n=8$ \\
\hline$L(\mathrm{~m})$ & Bending & Torsion & Bending & Torsion \\
\hline 50 & 150,250 & 150,820 & $150,250,450$ & 440,830 \\
60 & 150,430 & 150 & 150,450 & $150,430,830$ \\
70 & & 820 & 250,880 & 150,830 \\
80 & $150,430,870$ & 440,820 & 250,880 & $250,440,830$ \\
90 & 150,870 & $250,440,820$ & $150,450,880$ & $250,440,830$ \\
100 & 420 & 250,820 & 75,880 & \\
\hline
\end{tabular}

Table 7 Critical lengths $L_{c r}(\mathrm{~m})$ of bridge for travelling force $P=1,000 \mathrm{kN}$; bridge, only.

\begin{tabular}{|c|c|c|c|c|}
\hline \multirow[b]{2}{*}{$v(\mathrm{~km} / \mathrm{h})$} & \multicolumn{2}{|c|}{$n=10$} & \multicolumn{2}{|c|}{$n=8$} \\
\hline & Bending & Torsion & Bending & Torsion \\
\hline 50 & 75,84 & 54,95 & & \\
\hline 100 & 77,84 & 55 & & \\
\hline 200 & $54,63,97$ & 55 & $56,65,85$ & 55,64 \\
\hline 300 & 54,75 & 75 & 55,85 & 75 \\
\hline 600 & $65,78,84,95$ & 94 & $65,75,85,95$ & 66,85 \\
\hline 1,200 & $53,65,85,94$ & $57,75,94$ & $54,65,85$ & 64,93 \\
\hline
\end{tabular}

Table 8 Critical lengths $L_{c r}(\mathrm{~m})$ of bridge for travelling force $P=1,000 \mathrm{kN}$; task.

\begin{tabular}{|c|c|c|c|c|}
\hline \multirow[b]{2}{*}{$v(\mathrm{~km} / \mathrm{h})$} & \multicolumn{2}{|c|}{$n=10$} & \multicolumn{2}{|c|}{$n=8$} \\
\hline & Bending & Torsion & Bending & Torsion \\
\hline 50 & & 53 & & 95 \\
\hline 100 & & & & 54,95 \\
\hline 200 & $55,65,76,85$ & 64,95 & $55,65,75,95$ & 75,94 \\
\hline 300 & $55,65,76,94$ & 64,84 & 55 & 55,94 \\
\hline 600 & 84 & $66,75,85$ & $65,84,95$ & $66,75,93$ \\
\hline 1,200 & 54,85 & $56,74,84$ & $55,85,95$ & $56,65,75$ \\
\hline
\end{tabular}

Table 9 Critical lengths $L_{c r}(\mathrm{~m})$ of bridge for travelling force $P=200 \mathrm{kN}$; bridge, only.

\begin{tabular}{|c|c|c|c|c|}
\hline \multirow[b]{2}{*}{$v(\mathrm{~km} / \mathrm{h})$} & \multicolumn{2}{|c|}{$n=10$} & \multicolumn{2}{|c|}{$n=8$} \\
\hline & Bending & Torsion & Bending & Torsion \\
\hline \multicolumn{5}{|l|}{50} \\
\hline 100 & 85,95 & & & \\
\hline 200 & $55,65,85$ & 55 & $55,65,85$ & 65 \\
\hline 300 & $55,75,85$ & 55,75 & 55,85 & 75 \\
\hline 600 & $65,75,85$ & 65 & $55,75,85$ & 55,85 \\
\hline 1,200 & $54,64,75,85,95$ & $54,75,95$ & $65,85,95$ & 65,95 \\
\hline
\end{tabular}


Table 10 Critical lengths $L_{c r}(\mathrm{~m})$ of bridge for travelling force $P=200 \mathrm{kN}$; task.

\begin{tabular}{lllll}
\hline \multicolumn{1}{c}{$n=10$} & \multicolumn{1}{c}{$n=8$} \\
\hline$v(\mathrm{~km} / \mathrm{h})$ & Bending & Torsion & Bending & \\
\hline 50 & & & 95 & \\
100 & & & 65,85 & 55,75 \\
200 & $65,75,95$ & 65 & $55,75,85$ & 55,95 \\
300 & $55,65,75,95$ & $65,75,85,95$ & $55,65,85,95$ & $55,65,75$ \\
600 & 85 & $65,75,85,95$ & $55,85,95$ & $55,65,75,95$ \\
1,200 & $75,85,95$ & $55,75,85,95$ & & \\
\hline
\end{tabular}

(see Tables 7-10). It is the other interpretation of results presented in Section 4.1 in Tables 3-6 for $\mathrm{V}_{\text {cr. }}$. So, after analysis of some diagrams, following conclusions can be formulated. By small lengths of girder, the problem of instability of bridge girder does not appear. So, for girders with the length $L=50 \mathrm{~m}$ was not observed critical phenomena.

\section{Obtained Results}

The results presented above and in previous publications [8-15] permit to give general conclusion about efficacy of proposed innovative methods of calculation for dynamic behaviour of bridges and also tall buildings. It can be recommended. Many possible analyses of comparative calculations were presented by oral presentation and probably will be given in other future papers.

\section{Conclusions}

The applied method of analysis is probably at all new approach to evaluation of bridges behaviour. It is very simple and can be performed even by the easiest commercial program Excel, supported by other program calculating displacements. Here, it was used own program named DGPST_-giving deflections w or rotations $\Theta$ and value of main determinant of DSM $\left(K_{D}\right)$. The accuracy of calculations increases when increasing number $p$ of girder division on sections. On the other hand, such division should be not too dense. In analysed examples it seems, that $p=8$ or 10 was quite enough.

The more information, pictures, diagrams and conclusions were shown during oral presentation.

\section{References}

[1] Obrębski, J. B. 1991. Thin-Walled Elastic Straight Bars (Cienkościenne Sprężyste Pręty Proste). Warsaw: WPW, 452. (in Polish); 2-d Ed. 1999.

[2] Büttner, O., and Stenker, H. 1970. Metalleichtbauten, Volume 1, Ebene Raumstabwerke. Berlin: VEB Verlag für Bauwesen.

[3] Kaliski, S., et al. 1966. Vibrations and Waves (Drgania $i$ Fale). Warsaw: PWN. (in Polish).

[4] Nowacki, W. 1957. Structural Mechanics (Mechanika Budowli). Warsaw: PWN. (in Polish).

[5] Vlasov, W. Z. 1940. Tonkostiennyje Uprugije Stierżni. Moscow: Gosstrojizd.

[6] Obrębski, J. B. Strength of Materials. (Wytrzymatość Materiatów). Warsaw: AGAT, 238. (in Polish)

[7] Obrebski, J. B. 1979. Numerical Analysis and Synthesis of Large Structural Systems. (Analiza $i$ Synteza Numeryczna Wielkich Układów Konstrukcyjnych). IBTP Reports 24/1979, Warsaw. (in Polish).

[8] Obrębski, J. B. 2017. "3D-Time Space in Dynamical Analysis of Bridges." (Czasoprzestrzeń w analizie dynamicznej mostów). Problemy Mechatroniki: uzbrojenie, lotnictwo, inżynieria bezpieczeństwa 8 (3): 109-26. (in Polish).

[9] Obrębski, J. B. 2018. "Analysis of Critical State for Bridge in 3D-Time Space.” (Analiza stanów krytycznych mostu w czasoprzestrzeni). WAT, Pisz Poland. (in Polish) \& DOI:https://doi.org/10.17814/mechanik.2018.7.93

[10] Obrębski, J. B. 2018. "Analysis and Forms of Structures Critical States.” Presented at LSCE-2018, Łódź, Poland.

[11] Kączkowski, Z. 1975. "The Method of Finite Space-Time Elements in Dynamics of Struct." J. Techn. Physics. 16 (1): 69-84.

[12] Obrębski, J. B. 2004. "Examples of Some Parameters Influence on Bridges Behaviour under Moving Loadings." In Proceedings of Int. Conf. on Struct. Eng., Mechanics and Computat., Cape Town, South Africa, 859-64.

[13] Obrębski, J. B. 2019. “Analiza odpowiedzi mostu na przejazd obciazzenia." In Proceedings of the XXIII Miedzyn. Szkoła CAD, wytwarzania i eksploatacji, WAT, Pisz, Poland, 301-17. (in Polish) \& DOI 
10.15199/148.2019.10.4..

[14] Obrębski, J. B. 2008. "Multi Parametrical Instability of Straight Bars." Presented at IASS-IACM 6th Int. Conf. on Computation of Shell and Spatial Struct., Ithaca, USA.
[15] Obrębski, J. B. 2019. "Common Criterion for Structural Critical States." In Proceedings of the 7th Int. Conf. on Structural Engineering, Mechanics and Computation, Cape Town, South Africa. 